\title{
Proportion of pregnant women screened for hypertensive disorders in pregnancy and its associated factors within antenatal clinics of Kinshasa, Democratic Republic of Congo
}

Dalau Mukadi Nkamba ${ }^{1,2^{*}}$ (D), John Ditekemena ${ }^{1}$, Gilbert Wembodinga', Pierre Bernard ${ }^{3}$, Antoinette Tshefu $^{1}$ and Annie Robert ${ }^{2}$

\begin{abstract}
Background: Screening for hypertensive disorders in pregnancy (HDP) is clinically important for identifying women at high risk, and planning early preventative interventions to improve pregnancy outcomes. Several studies in developing countries show that pregnant women are seldom screened for HDP. We conducted a study in Kinshasa, DR Congo, in order to assess the proportion of pregnant women screened for HDP, and to identify factors associated with the screening.

Methods: We conducted a facility-based cross-sectional study in a random sample of 580 pregnant women attending the first antenatal visit. Data collection consisted of a review of antenatal records, observations at the antenatal care services, and interviews. A pregnant woman was considered as screened for HDP if she had received the tree following services: blood pressure measurement, urine testing for proteinuria, and HDP risk assessment. Multivariable logistic regression, with generalized estimating equations, was used to identify factors associated with the screening for HDP.

Results: Of the 580 pregnant women, 155 (26.7\%) were screened for HDP, 555 (95.7\%) had their blood pressure checked, 347(59.8\%) were assessed for risk factors of HDP, and 156 (26.9\%) were tested for proteinuria. After multivariable analysis, screening for HDP was significantly higher in parous women ( $\mathrm{AOR}=2.09 ; 95 \% \mathrm{Cl}, 1.11-3.99 ; P=0.023$ ), in women with a gestational age of at least 20 weeks ( $A O R=5.50 ; 95 \% \mathrm{Cl}, 2.86-10.89 ; P=0.002)$, in women attending in a private clinic $(A O R=3.49 ; 95 \% \mathrm{Cl}, 1.07-11.34 ; P=0.038)$, or in a hospital $(A O R=3.24 ; 95 \% \mathrm{Cl}, 1.24-8.47 ; P=0.017)$, and when no additional payment was required for proteinuria testing at the clinic ( $A O R=2.39 ; 95 \% \mathrm{Cl}, 1.14-5.02 ; P=0.021)$.

Conclusion: Our results show that screening for HDP during the first antenatal visit in Kinshasa is not universal. The factors associated with screening included maternal as well as clinics' characteristics. More effort should be made both at maternal and clinic levels to improve the screening for HDP in Kinshasa.
\end{abstract}

Keywords: Screening, Hypertensive disorders in pregnancy, Kinshasa

\footnotetext{
* Correspondence: dkanba@yahoo.fr

'Kinshasa School of Public Health, Faculty of Medicine, University of Kinshasa, Kinshasa, Democratic Republic of Congo

${ }^{2}$ Institut de Recherche Expérimentale et Clinique (IREC), Pôle d'Epidémiologie

et Biostatistique (EPID), Université catholique de Louvain (UCLouvain),

Brussels, Belgium

Full list of author information is available at the end of the article
}

(c) The Author(s). 2019 Open Access This article is distributed under the terms of the Creative Commons Attribution 4.0 International License (http://creativecommons.org/licenses/by/4.0/), which permits unrestricted use, distribution, and reproduction in any medium, provided you give appropriate credit to the original author(s) and the source, provide a link to the Creative Commons license, and indicate if changes were made. The Creative Commons Public Domain Dedication waiver (http://creativecommons.org/publicdomain/zero/1.0/) applies to the data made available in this article, unless otherwise stated. 


\section{Background}

Hypertensive disorders in pregnancy (HDP) are the second most common cause of maternal mortality worldwide [1]. Most deaths are avoidable and occur in low- and middle-income countries (LMIC), due to a lack or a delay in identifying women at high-risk, and in their treatment [2-5]. HDP screening is an essential element of antenatal care (ANC) that allows the identification of women at high risk of developing HDP or HDP-related complications, and the implementation of preventive interventions for improving perinatal outcomes [6-12]. Screening for HDP at the first antenatal visit includes blood pressure measurement, urine testing for proteinuria, and identification of maternal risk factors [13-17]. The National Institute for Health and Clinical Excellence (NICE) and the American College of Obstetricians and Gynecologists (ACOG) have provided a list of maternal risk factors to be assessed at the first antenatal visit $[13,18]$. To prevent HDP in LMIC, where biomarkers are not available to identify women at high risk, the International Society for the Study of Hypertension in Pregnancy (ISSHP) recommends the use of low dose aspirin started before 16 weeks of pregnancy in women with any of the following risk factors: previous preeclampsia, chronic hypertension, underlying renal disease, diabetes mellitus, obesity, and antiphospholipid antibody syndrome [17].

In sub-Saharan Africa, while blood pressure is measured in more than half of antenatal attendees, proteinuria testing is performed less frequently [19-23]. Studies report $10 \%$ of women tested for proteinuria in Mozambique [21], 23\% in Zambia 23\% [19], and 32\% in Ethiopia [24]. In a study in six sub-Saharan Africa countries including Tanzania and Rwanda, only $46 \%$ of women had a urine test for proteinuria [25]. According to the Demographic and Health Survey (DHS) conducted in 2014 in Democratic Republic of Congo (DRC), urine samples were collected during antenatal visits in 94.1 and $53.1 \%$ of women who delivered in the five years preceding the survey in Kinshasa and DRC, respectively [26]. However, laboratory tests performed on these urine samples were not specified. According to the World Health Organization (WHO), the maternal mortality is estimated at 693 deaths per 100,000 live births in the DRC [27]. This is higher than one might expect based on a high rate of antenatal care attendance (89\%) and a high rate of skilled attendance at delivery $(80 \%)$ [26]. According to the DRC's National Health Information System (NHIS), 561 (52\%) of the 1088 cases of preeclampsia reported in Kinshasa in 2017 developed eclampsia [28], making HDP the major cause of adverse pregnancy outcomes. During the first six months of 2018, HDP accounted for 841 (23\%) of the 3656 maternal deaths that were reported to the DRC's maternal death surveillance system [29]. Given that HDP are the second most common cause of maternal mortality in DRC [29], preventing HDP and HDP-related adverse pregnancy outcomes can contribute to the attainment of Sustainable Development Goal 3, which aims to reduce the maternal and neonatal mortality [30]. To our knowledge, no study to date has evaluated the screening for HDP during antenatal care in Kinshasa. We conducted the current study to determine the proportion of pregnant women screened for HDP during their first ANC visit in Kinshasa, and to identify factors associated with HDP screening.

\section{Methods}

\section{Study setting}

The study was carried out in 58 clinics that participated in the HDP Service Availability and Readiness Assessment (SARA) study that was previously conducted in Kinshasa. These 58 clinics (30 primary, 26 secondary and 2 tertiary) were selected using the stratified random procedure from a sampling frame of 837 primary, 138 secondary and 2 tertiary facilities that provide emergency obstetric and neonatal care (EmONC). In the DRC's tierced health system, primary health centres (PHCs) provide basic curative and preventive services. The district hospitals (or Referral Health Centres where no district hospitals exist) are secondary level facilities, providing comprehensive emergency obstetric and neonatal care, and represent referral facilities for PHCs. Tertiary facilities include provincial reference hospitals and teaching hospitals. However, some PHCs refer directly to tertiary-level facilities [31].

\section{Study design, population, and sample size}

We conducted a facility-based cross-sectional study among pregnant women attending the first ANC visit in the 58 above mentioned clinics. The sample size was obtained by using the formula for a single population proportion. Using a non-informative prior of $50 \%$ for the proportion of women screened for HDP, a margin error of $5 \%$, a non-response rate of $10 \%$, and a design effect of 1.3 based on our pilot study, a sample of 555 pregnant women was required. This sample size was divided by 58 (number of clinics) to get a minimum number needed per clinic, i.e. $555 / 58=9.6$, which was rounded up to 10 , leading to a final sample size of 580 women.

\section{Sampling procedure}

For each clinic, we estimated the average number of first ANC visits per month (Yi; i stands for clinic number) from the most recent quarterly report of the clinic. This average number of first ANC visits (Yi) was considered as a sampling frame. We calculated $\mathrm{Xi}$, the sampling step, by dividing $\mathrm{Yi}$ by 10 , because 10 was the targeted sample size for each clinic. A number between 1 and $\mathrm{Xi}$, 
called Wi hereafter, was then chosen at random with a uniform generator. In each clinic, all women presenting for a first ANC visit were consecutively numbered. The pregnant woman presenting with the number $\mathrm{Wi}$ in the sequential list of consultations was kept as the first one in our sample. Then, the 9 remaining pregnant women were systematically chosen at each Xi step in the list of consultations. In other words, all women numbered $\mathrm{Wi}+\mathrm{k}^{*} \mathrm{Xi}$ (for $\mathrm{k}=0$ to 9) were sampled among the consecutive list of those who presented at the ANC service during the one-month period of data collection.

\section{Operational definitions}

We used the following definitions in assessing the screening for HDP, and analyzing results:

\section{HDP screening package}

The entire HDP screening package consists of 1) blood pressure measurement, 2) urine test for proteinuria, and 3) HDP risk assessment.

\section{Risk of HDP}

Known risk factors for HDP including a history of diabetes, HDP in a previous pregnancy (if parous), a history of chronic hypertension, a history of renal disease.

\section{HDP risk assessment}

Enquiring about at least one of the following risk factors: HDP in a previous pregnancy (if parous), a history of chronic hypertension, a history of diabetes, a history of renal disease.

\section{Woman screened for HDP}

A pregnant woman who had received the entire HDP screening package during the ANC visit.

\section{Late ANC booking}

First ANC visit beyond 16 weeks of pregnancy.

\section{Data collection}

Twelve physicians were recruited as surveyors, based on their previous experience in data collection, and two health officers as supervisors. Surveyors and supervisors were trained during five days before data collection. The training addressed the aim of the study, all procedures, and data collection techniques. We used a study questionnaire on maternal socio-demographic and obstetrical characteristics, and on clinics' and ANC providers' characteristics. A checklist for direct observation of an antenatal consultation was also used. This checklist focused on the screening for HDP. For each selected pregnant woman, a surveyor observed ANC provider conducting ANC consultation. He checked whether the ANC provider enquired about risk factors for HDP, whether he measured blood pressure, and whether he performed urine test for proteinuria. When the ANC consultation was completed, surveyors directly interviewed the woman about her socio-demographic and obstetrical data. Prior to the data collection, the questionnaire was pilot-tested in 10 clinics not included in this study. Data were collected between October 2017 and January 2018.

\section{Data analysis}

Data were entered into EpiData software version 3.1 database and subsequently exported in Stata 14 for statistical analyses. We computed normalized weights to account for the unequal inclusion probability of pregnant women. The weights were obtained by inverting the inclusion probability of pregnant women. The inclusion probability of a pregnant woman was obtained by dividing 10 by the average number of pregnant women per month in the clinic. Weights were then normalized to set the weighted sample size to 580. To obtain normalized weights, we multiplied the weights by the unweighted sample size $(n=580)$ and divided by the sum of weights. All analyses were weighted using normalized weights. There was no missing data. During descriptive analysis, categorical variables were summarized using weighted proportions. Continuous variables were summarized using weighted mean and standard deviation (SD) if normal distributed, or median and interquartile range (IQR) otherwise. Secondary and tertiary health facilities were grouped into one category named "hospitals", as they all represent referral units for PHCs.

We computed weighted proportions of pregnant women who received an antenatal service by type of facilities (PHCs or hospitals; or private and public), and by gestational age (less than 16 weeks, and 16 weeks and above), and compared them using a weighted chi square test.

Our dependent variable was binary (screened for HDP, yes or no). We used logistic regression analysis, with generalized estimating equations (GEE), to control for correlation among pregnant women at the same clinic. All variables with a $P$-value less than 0.25 in simple regression were candidates for multivariable analysis. If a strong correlation was noticed between two explanatory variables, one of the two was eliminated to avoid multicollinearity. Multicollinearity among independent variables was checked using the variance inflation factor (VIF). A VIF larger than 10 was indicative of the multicollinearity [32]. Study results are presented as odds ratios (OR) or adjusted odds ratios (AOR) with 95\% confidence intervals $(95 \% \mathrm{CI})$. The statistical significance level was set to 0.05 . 


\section{Results}

\section{Characteristics}

Of the 58 clinics, 41 (70.7\%) were private and 17 (29.3\%) were public. The median number of pregnant women attended per month per clinic was 50 (IQR: 37 to 63) (Table 1). The median age of the 580 pregnant women was 28 (IQR: 23 to 33 ) years (range, 15 to 44 years). The majority of women (60\%) reached at least a secondary level of schooling. Roughly 83\% (95\% IC, 78.9-86.9\%) of women booked ANC beyond 16 weeks of pregnancy. In both PHCs and hospitals, women's socio-demographic characteristics were comparable (Table 2).

\section{Screening status for HDP}

Out of the 580 pregnant women, 155 (26.7\%; 95\% IC, 18.4-37.1\%) were screened for HDP, 555 (95.7\%; 95\% IC, 90.1-98.2\%) had their blood pressure checked, 347 (59.8\%; 95\% IC, 49.6-69.2\%) were assessed for risk factors of HDP, and 156 (26.9\%; 95\% IC, 18.6-37.4\%) were tested for proteinuria (Table 3 ). The proportion of pregnant women whose blood pressure was measured was significantly higher in hospitals than in

Table 1 Characteristics of the 58 participating antenatal clinics in Kinshasa

\begin{tabular}{|c|c|}
\hline \multirow{2}{*}{\multicolumn{2}{|c|}{$\begin{array}{l}\text { Characteristics } \\
\text { Number of pregnant women attended }{ }^{\mathrm{a}} \text { —no./mth }\end{array}$}} \\
\hline & \\
\hline Median (IQR) & $50(37-63)$ \\
\hline \multicolumn{2}{|l|}{ Type-no. (\%) } \\
\hline Primary & $30(51.7)$ \\
\hline Secondary & $26(44.8)$ \\
\hline Tertiary & $2(3.5)$ \\
\hline \multicolumn{2}{|c|}{ Ownership—no. (\%) } \\
\hline Private & $41(70.7)$ \\
\hline Public & $17(29.3)$ \\
\hline \multicolumn{2}{|l|}{ Funded-no. (\%) } \\
\hline Yes & $35(60.3)$ \\
\hline No & $23(39.7)$ \\
\hline \multicolumn{2}{|c|}{ Location-no. (\%) } \\
\hline Rural area & $7(12.1)$ \\
\hline Urban area & $51(87.9)$ \\
\hline \multicolumn{2}{|c|}{ Proteinuria test available ${ }^{\mathrm{b}}$ —no. (\%) } \\
\hline Yes & $39(67.2)$ \\
\hline No & $19(32.8)$ \\
\hline \multicolumn{2}{|c|}{ Additional payment required for proteinuria testing ${ }^{c}$ - no. (\%) } \\
\hline Yes & $50(86.2)$ \\
\hline No & $8(13.8)$ \\
\hline
\end{tabular}

Abbreviations: IQR Interquartile range, mth months; no number ${ }^{a}$ The mean number of pregnant women attended monthly per clinic ${ }^{b}$ Dipsticks or acetic acid available during the study period 'Whether women have to pay extra money to be tested
Table 2 Characteristics of interviewed pregnant women attending antenatal care in 30 Primary Health Centres, and 28 hospitals sampled in Kinshasa

\begin{tabular}{|c|c|c|c|}
\hline Characteristics & $\begin{array}{l}\text { Primary health } \\
\text { centres }\left(n^{a}=260\right)\end{array}$ & $\begin{array}{l}\text { Hospitals } \\
\left(n^{a}=320\right)\end{array}$ & $\begin{array}{l}\text { All } \\
\left(n^{a}=580\right)\end{array}$ \\
\hline \multicolumn{4}{|l|}{ Maternal age-yrs } \\
\hline Median (IQR) & $27(23-33)$ & $29(23-34)$ & $28(23-33)$ \\
\hline \multicolumn{4}{|l|}{ Age group-no. (\%) } \\
\hline 15-19 & $32(12.4)$ & $50(15.6)$ & $82(14.1)$ \\
\hline $20-34$ & 195(74.8) & 197(61.6) & $392(67.6)$ \\
\hline $35-44$ & $33(12.8)$ & $73(22.8)$ & $106(18.3)$ \\
\hline \multicolumn{4}{|l|}{ Marital status-no. (\%) } \\
\hline Married/in union & 232(89.2) & $271(84.7)$ & $503(86.7)$ \\
\hline Single/Separated & 28(10.8) & $49(15.3)$ & 77(13.3) \\
\hline \multicolumn{4}{|l|}{ Scholarship-no. (\%) } \\
\hline Illiterate & $14(5.4)$ & $2(0.6)$ & $16(2.8)$ \\
\hline Primary & $106(40.8)$ & $109(34.1)$ & 215(37.1) \\
\hline Secondary or technical & $105(40.4)$ & $139(43.4)$ & $244(42.0)$ \\
\hline University or high school & $35(13.4)$ & $70(21.9)$ & $105(18.1)$ \\
\hline \multicolumn{4}{|l|}{ Occupation-no. (\%) } \\
\hline Housewife & 155(59.6) & $176(55.0)$ & $331(57.1)$ \\
\hline With a salary & $105(40.4)$ & $144(45.0)$ & $249(42.9)$ \\
\hline \multicolumn{4}{|l|}{ Gestational age-weeks } \\
\hline Median (IQR) & $22(18-25)$ & $23(18-27)$ & $22(18-25)$ \\
\hline \multicolumn{4}{|l|}{ Group-no. (\%) } \\
\hline$<16$ weeks & $43(16.5)$ & $54(16.7)$ & $97(16.9)$ \\
\hline$\geq 16$ weeks & $217(83.5)$ & 266(83.3) & 483(83.1) \\
\hline \multicolumn{4}{|l|}{ Gravidity—no. (\%) } \\
\hline 1 & 47(18.1) & $80(25.0)$ & $127(21.9)$ \\
\hline 2 to 4 & $175(67.3)$ & $186(58.1)$ & $361(62.2)$ \\
\hline$\geq 5$ & $38(14.6)$ & $54(16.9)$ & $92(15.9)$ \\
\hline \multicolumn{4}{|l|}{ Parity-no. (\%) } \\
\hline 0 & $66(25.4)$ & $89(27.8)$ & $155(26.7)$ \\
\hline 1 to 3 & 168(64.6) & 193(60.3) & $361(62.2)$ \\
\hline$\geq 4$ & $26(10.0)$ & 38(11.9) & 64(11.1) \\
\hline
\end{tabular}

Abbreviations: yrs. years; IQR Interquartile range

a: weighted number of pregnant women

PHCs $(99.4 \%$ vs 91.1\%; $P=0.009)$. There were no significant differences between PHCs and hospitals in the proportion of women tested for proteinuria and those assessed for risk factors (Table 3).

In hospitals, blood pressure measurement was significantly less prevalent among women attending before 16 weeks of pregnancy, as compared to those attending at 16 weeks and above $(P=0.042)$. Both in PHCs and in hospitals, urine test for proteinuria was significantly less performed in women attending before 16 weeks, than those at at least 16 weeks (Table 4). There were significantly more women tested for proteinuria in private 
Table 3 Weighted proportion of pregnant women who received antenatal service at the time of the survey, according to types of clinics $^{c}$

\begin{tabular}{|c|c|c|c|c|}
\hline Service received & $\begin{array}{l}\text { All } \\
(n=580)\end{array}$ & $\begin{array}{l}\text { Primary Health } \\
\text { Centres }(n=260)\end{array}$ & $\begin{array}{l}\text { Hospitals } \\
(n=320)\end{array}$ & $\begin{array}{l}\text { Weighted } X^{2} \\
P \text {-value }\end{array}$ \\
\hline Checking history of renal disease & $7(1.2)$ & $3(1.2)$ & $4(1.3)$ & 0.91 \\
\hline Checking history of HDP in previous pregnancies ${ }^{a}$ & $103(22.7)$ & $50(23.5)$ & $53(22.1)$ & 0.89 \\
\hline Urine test for proteinuria & $156(26.9)$ & $55(21.2)$ & $101(31.6)$ & 0.23 \\
\hline Checking history of diabetes & $196(33.8)$ & $80(30.8)$ & $116(36.3)$ & 0.61 \\
\hline Checking history of hypertension & $198(34.1)$ & $83(31.9)$ & $115(35.9)$ & 0.63 \\
\hline Assessing body mass index & $248(42.8)$ & $89(34.2)$ & $159(49.7)$ & 0.12 \\
\hline Checking at least one risk factor ${ }^{\mathrm{b}}$ & $347(59.8)$ & $138(53.1)$ & $209(65.3)$ & 0.21 \\
\hline Blood pressure measurement & $555(95.7)$ & $237(91.2)$ & $318(99.4)$ & 0.009 \\
\hline
\end{tabular}

Abbreviations: HDP Hypertensive disorders in pregnancy

${ }^{a}$ Only in 453 women with previous pregnancies: 213 in Primary Health Centres, 240 in hospitals;

${ }^{b}$ Checking at least one of the following risk factors: HDP in previous pregnancies (if parous), history of chronic hypertension, history of diabetes, and history of renal disease

'Data were weighted according to normalized weights

than in public clinics $(32 \%$ vs $12 \% ; P<0.01)$. There was no significant difference in risk assessment and blood pressure measurement between public and private clinics (Fig. 1).

Screening for HDP was significantly lower in women attending before 16 weeks, than in those attending at at least 16 weeks, both in PHCs and hospitals (Fig. 2).

\section{Factors associated with screening for HDPS}

After multivariable analysis, screening for HDP was significantly higher in parous women (AOR $=2.09$; 95\% CI, 1.11-3.99; $P=0.023$ ), in women with a gestational age of at least 20 weeks (AOR $=5.50$; 95\% CI, 2.86$10.89 ; P=0.002$ ), in women attending in a private clinic (AOR $=3.49 ; 95 \% \mathrm{CI}, 1.07-11.34 ; P=0.038)$, or in a hospital $(\mathrm{AOR}=3.24 ; 95 \% \mathrm{CI}, 1.24-8.47 ; P=0.017)$, and when no additional payment was required for proteinuria testing at the clinic $(\mathrm{AOR}=2.39 ; 95 \% \mathrm{CI}$, 1.14-5.02; $P=0.021$ ) (Table 5).

\section{Discussion}

Our study showed a low level of provision of screening for HDP in Kinshasa, with only $26.7 \%$ of women fully screened. Nearly all women had their blood pressure checked. The failure of complete HDP screening was a lack of ascertaining risk factors in $40 \%$, and a lack of urine testing for proteinuria in $73 \%$. The latter made the overall gap in the quality of screening so high. Screening for HDP was significantly higher in parous women, in women with a gestational age of at least 20 weeks, in women attending in a private clinic or in a hospital, and when no additional payment was required for proteinuria testing at the clinic.

Table 4 Weighted proportion of pregnant women who received antenatal service at the time of the survey, in Primary Health Centres and in hospitals, according to the gestational age ${ }^{b}$

\begin{tabular}{|c|c|c|c|c|c|c|}
\hline \multirow[t]{3}{*}{ Service received } & \multicolumn{3}{|c|}{ Primary health centers } & \multicolumn{3}{|l|}{ Hospitals } \\
\hline & \multicolumn{6}{|c|}{ Gestational age in weeks } \\
\hline & $\begin{array}{l}<16 \text { weeks } \\
(n=43)\end{array}$ & $\begin{array}{l}\geq 16 \text { weeks } \\
(n=217)\end{array}$ & $\begin{array}{l}\text { Weighted } X^{2} \\
P \text {-value }\end{array}$ & $\begin{array}{l}<16 \text { weeks } \\
(n=53)\end{array}$ & $\begin{array}{l}\geq 16 \text { weeks } \\
(n=267)\end{array}$ & $\begin{array}{l}\text { Weighted } X^{2} \\
P \text {-value }\end{array}$ \\
\hline Checking history of renal disease & 2.2 & 0.9 & 0.001 & 1.4 & 1.2 & 0.89 \\
\hline Urine test for proteinuria & 6.8 & 24.2 & 0.02 & 10.7 & 35.7 & 0.02 \\
\hline Checking history of HDP in previous pregnancies & 15.7 & 24.8 & 0.102 & 8.9 & 24.7 & 0.033 \\
\hline Assessing body mass index & 17.2 & 37.6 & 0.034 & 30.2 & 53.6 & 0.013 \\
\hline Checking history of hypertension & 18.9 & 34.4 & 0.11 & 45.7 & 34.1 & 0.19 \\
\hline Checking history of diabetes & 21.9 & 32.8 & 0.16 & 31.5 & 37.1 & 0.39 \\
\hline Checking at least one risk factor ${ }^{a}$ & 39.6 & 55.6 & 0.13 & 58.7 & 66.8 & 0.43 \\
\hline Blood pressure measurement & 91.1 & 91.1 & 0.95 & 96.6 & 100.0 & 0.042 \\
\hline
\end{tabular}

Abbreviations: HDP Hypertensive disorders in pregnancy, $X^{2}$ : Chi square

${ }^{a}$ Checking at least one of the following risk factors: HDP in previous pregnancies (if parous), history of chronic hypertension, history of diabetes, and history of renal disease

${ }^{\mathrm{b}}$ Data were weighted according to normalized weights 

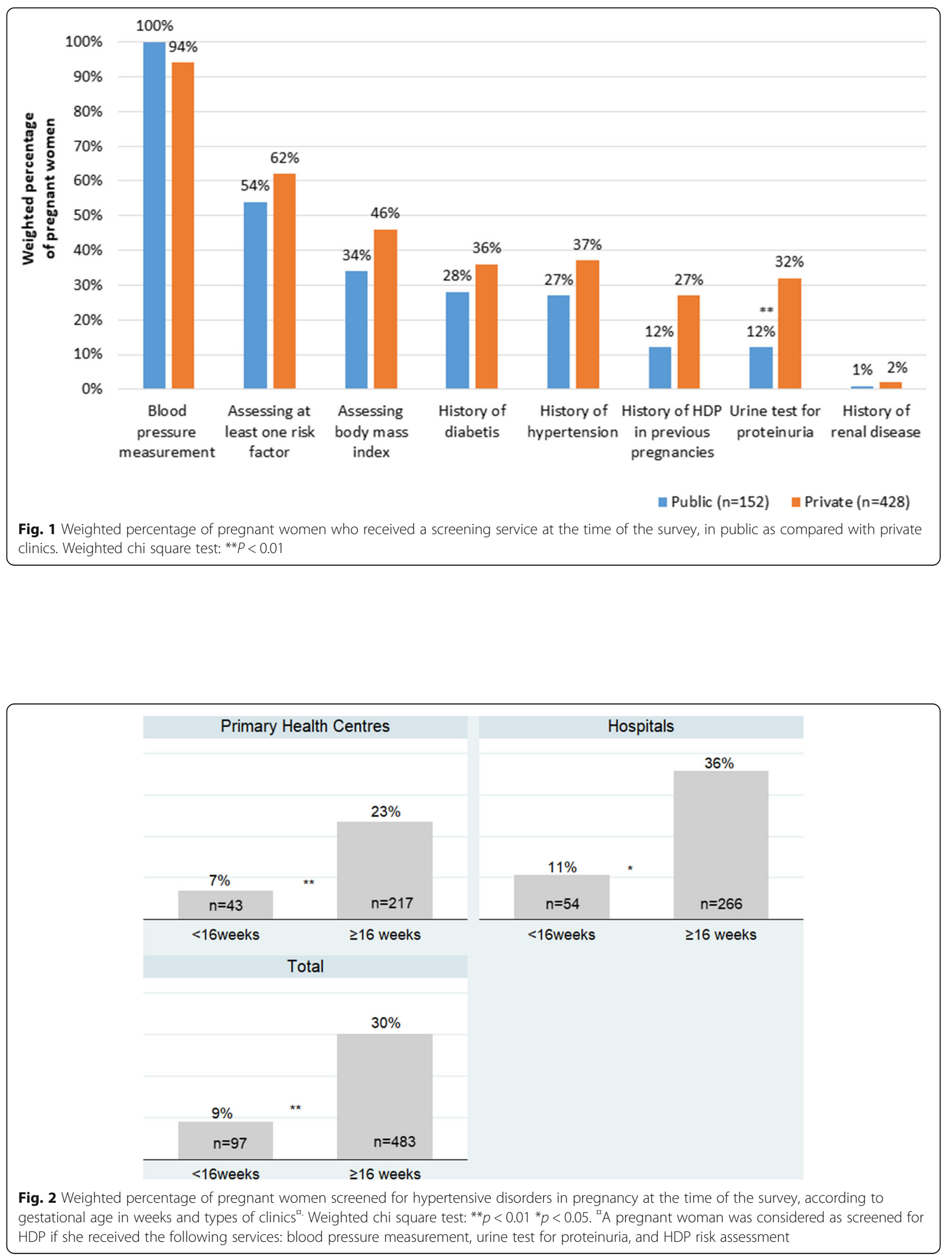
Table 5 Factors associated with the screening for hypertensive disorders in pregnancy in 580 pregnant women attending antenatal care in 58 clinics of Kinshasa, using weighted GEE logistic regression model

\begin{tabular}{|c|c|c|c|c|c|}
\hline Factors & no./N (\%) & Crude OR $(95 \%$ IC) & $P$-Value & Adjusted OR (95\% IC) & $P$-Value \\
\hline Parity & & & 0.02 & & 0.023 \\
\hline 0 & 24/155 (15.5) & 1 & & 1 & \\
\hline$\geq 1$ & $131 / 426(30.8)$ & $1.84(1.11-3.04)$ & & $2.09(1.11-3.99)$ & \\
\hline Maternal age- $-y r$ & & & 0.036 & & - \\
\hline $15-19$ & $11 / 82(13.4)$ & 1 & & & \\
\hline$\geq 20$ & 144/498 (28.9) & $2.01(1.04-3.84)$ & & & \\
\hline Marital status & & & 0.35 & & - \\
\hline Maried/in union & 135/503 (26.8) & $1.44(0.67-3.08)$ & & & \\
\hline Single/separated & 20/77 (25.9) & 1 & & & \\
\hline Gestational age-wks & & & 0.006 & & 0.002 \\
\hline$<20$ & $11 / 189(5.8)$ & 1 & & 1 & \\
\hline$\geq 20$ & 144/391 (36.8) & $4.24(2.39-7.50)$ & & $5.50(2.86-10.89)$ & \\
\hline Schooling & & & 0.11 & & 0.55 \\
\hline Primary or less & $41 / 231(17.7)$ & 1 & & 1 & \\
\hline Secondary or more & $114 / 349(32.7)$ & $1.66(0.90-3.06)$ & & $1.92(0.98-3.74)$ & \\
\hline Occupation & & & 0.93 & & - \\
\hline Housewife & 86/331 (25.9) & 1 & & & \\
\hline Employed & $69 / 249(27.7)$ & $1.02(0.73-1.42)$ & & & \\
\hline Clinic ownership & & & 0.002 & & 0.038 \\
\hline Private & 136/428(31.8) & $3.31(1.38-7.87)$ & & $3.49(1.07-11.34)$ & \\
\hline Public & 19/152 (12.5) & 1 & & 1 & \\
\hline Type of the clinic & & & 0.19 & & 0.017 \\
\hline PHCs & $54 / 260(20.8)$ & 1 & & 1 & \\
\hline Hospitals & 101/320 (31.6.) & $1.76(0.75-4.13)$ & & $3.24(1.24-8.47)$ & \\
\hline Funded clinic & & & 0.93 & & - \\
\hline Yes & 99/373 (26.5) & 1 & & & \\
\hline No & $56 / 207(27.1)$ & $1.04(0.41-2.63)$ & & & \\
\hline \multicolumn{3}{|c|}{ Women attended by health provider trained in HDP management } & 0.79 & & - \\
\hline Yes & $40 / 150(26.7)$ & 1 & & & \\
\hline No & $115 / 430(26.8)$ & $1.01(0.49-2.53)$ & & & \\
\hline Location & & & 0.93 & & - \\
\hline Rural area & $10 / 44(22.7)$ & 1 & & & \\
\hline Urban area & $145 / 536(27.1)$ & $1.16(0.39-3.8)$ & & & \\
\hline \multicolumn{3}{|c|}{ Additional payment required for proteinuria testing } & 0.001 & & 0.021 \\
\hline No & $46 / 91(50.5)$ & $3.45(1.64-7.22)$ & & $2.39(1.14-5.02)$ & \\
\hline Yes & $109 / 489(22.3)$ & 1 & & 1 & \\
\hline
\end{tabular}

Abbreviations: GEE Generalized estimating equations, OR Odds ratio, HDP Hypertensive disorders in pregnancy; yrs. years, wks weeks, no number of women screened; $\mathrm{N}$ total number of women

The prevalence of blood pressure measurement in our study is consistent with those reported in Kenya (96\%) and Nigeria (92\%); but higher than the range of 45 to $89 \%$ reported in other developing countries such as Mozambique and Ethiopia [25, 33-35]. Our findings regarding proteinuria testing are similar to those reported in Rwanda (31\%) and Madagascar (29\%), but lower than those reported in Tanzania (40\%), in Kenya (59\%) and in Ethiopia (66\%) [25]. Despite the availability of urine tests in two-thirds of health facilities in Kinshasa, we found a low provision of urine testing for proteinuria. This suggests that other factors were not 
captured by our study, including poor knowledge among ANC providers or a lack of consistent national guidelines for the screening for HDP $[25,36]$.

Risk factors of HDP can be ascertained by a simple anamnesis of a woman during her ANC consultation [17]. In our study, only $59.8 \%$ of pregnant women were assessed for risk factors of HDP. To assess risk factors, providers should be aware of them. In studies from Bangladesh and Nigeria, only 2 and 15\% of ANC providers were aware of risk factors for HDP, respectively $[37,38]$. The failure to assess women for risk factors of HDP in Kinshasa may be a consequence of providers' knowledge gaps, but the point needs to be investigated.

The low provision of screening for HDP in Kinshasa (26.7\%) may also be due to a lack of consistent national guidelines regarding the prevention of HDP, which can subsequently induce knowledge gaps among health providers [39]. This low provision of screening for HDP raises the issue of the quality of antenatal care services, and implies a missed opportunity to prevent HDP which account for up to $23 \%$ of maternal deaths in DRC [29].

Screening for HDP is critically important in PHCs, even if they are generally less equipped, because it allows timely referral of the woman to a higher level facility with more appropriate surveillance tools $[2,17,40,41]$. Our findings indicate that women having ANC visits in PHCs were less likely to be screened than those in hospitals. This finding is consistent with other studies reporting also a low provision of maternal health services in PHCs compared to hospitals [42]. More efforts should be devoted to promoting systematic screening for HDP in PHCs as they represent the first contact health facility in Kinshasa.

Studies have shown the benefit of aspirin in the prevention of HDP in high-risk women when it is started before 16 weeks of pregnancy, or definitely no later than 20 weeks $[6,17]$. To be effective, such prevention requires on one hand that pregnant women book ANC during the first trimester of pregnancy, and that ANC providers systematically screen women to identify those at a high risk of developing HDP, on the other hand. Our study found a high prevalence of late ANC booking (83.3\%). This finding is consistent with a previous study from DRC in which the magnitude of late ANC booking was $82.4 \%$ [43], suggesting that late ANC booking is a public health issue in DRC. Surprisingly, women booking ANC beyond 20 weeks of pregnancy were more likely to be screened than those booking before 20 weeks. One possible explanation is that preeclampsia, the most prevalent HDP, arises after the 20th week of pregnancy [17]. Hence, ANC providers would be inadvertently more interested in screening women with a gestational age greater than 20 weeks, rather than those with a less advanced pregnancy.
Our findings alert health authorities to the low level of screening for HDP in Kinshasa. With such low provision of screening, it is not surprising that HDP remain a public health problem in Kinshasa [29, 44]. The study highlights the need for improving the provision of screening for HDP in order to contribute to reducing HDP-related morbidity and mortality.

To improve the screening for HDP in Kinshasa, interventions targeting both community and health system are needed. At the community level, pregnant women should be advised to book ANC in an earlier stage of pregnancy, in order to benefit from early screening for HDP [6]. At the health system level, there is a need to update national ANC guidelines and to train health providers accordingly. There is also a need to enhance the availability of urine tests for protein, and without any additional payment from women [45].

The main strength of this study is that data were collected during an actual ANC consultation, avoiding bias due to self-reporting or recall bias. To our knowledge, this is the first study in Kinshasa focusing on the screening for HDP during antenatal care.

Nonetheless, the study has some limitations, as the provision of antenatal service was assessed by direct observation of an antenatal consultation, health providers might have made an extra effort to give their best quality service at the time when the research team visited the clinic. We attempted to mitigate this Hawthorne effect by having data collectors stay of several days, which may have helped to reduce ANC provider awareness of the presence of the data collector.

\section{Conclusion}

Our results show that screening for HDP during the first antenatal visit in Kinshasa is not universal. The gap in the quality of screening was in the identification of maternal risk factors, and a lack of urine testing for proteinuria. The factors associated with the screening included maternal as well as clinics' characteristics. Our study highlights the need to improve the availability and provision of urine testing for proteinuria as well as risk factors assessment during the first ANC visit. More effort should also be made at the women level to increase early ANC booking.

\footnotetext{
Abbreviations

ACGO: American College of Obstetricians and Gynecologists; ANC: Antenatal care; AOR: Adjusted odds ratio; Cl: confidence interval; DHS: Demographic and Health Survey; DRC: Democratic Republic of Congo; EmONC: emergency obstetric and neonatal care; GEE: generalized estimating equations; HDP: Hypertensive disorders in pregnancy; IQR: interquartile range; LMIC: Low- and Middle-Income Countries; NHIS: National Health Information System; NICE: National Institute for Health and Clinical Excellence; OR: Crude odds ratio; PHCs: Primary health centres; SARA: Service Availability and Readiness Assessment study; SD: Standard deviation; VIF: Variance inflation factor
} 


\section{Acknowledgments}

We are thankful to the United States Agency for International Development (USAID) for funding the thesis of Nkamba Mukadi Dalau. This work is a preliminary report of data.

collected for his thesis. This finding source is non-commercial. We thank Professors Carl Bose and Patrick Kayembe for their useful inputs on the manuscript.

\section{Authors' contributions}

DMN, JD and AR designed the research; DMN conducted the fieldwork, analyzed data, and drafted the manuscript. JD, AR, GW, AT, and PB critically revised the drafted manuscript. All authors read and approved the final manuscript.

\section{Funding}

This study was carried out with funding provided by the United States Agency for International Development (USAID). USAID didn't have any role in study design, data collection and analysis, manuscript development or decision to publish.

\section{Availability of data and materials}

The datasets used during the current study are available from the corresponding author on reasonable request.

\section{Ethics approval and consent to participate}

The study protocol was approved by the institutional review board of the Kinshasa School of Public Health ( $n^{\circ}$ ESP/CE/035/2017). Participants were informed using the informed consent statement, detailing all relevant aspects of the study. All study participants provided signed written informed consent. For a pregnant woman under 18 years old, a written consent was also obtained from a legal representative, in addition to the assent from the woman herself.

\section{Consent for publication}

Not applicable.

\section{Competing interests}

The authors declare that they have no competing interests.

\section{Author details}

'Kinshasa School of Public Health, Faculty of Medicine, University of Kinshasa, Kinshasa, Democratic Republic of Congo. ${ }^{2}$ Institut de Recherche Expérimentale et Clinique (IREC), Pôle d'Epidémiologie et Biostatistique (EPID), Université catholique de Louvain (UCLouvain), Brussels, Belgium. ${ }^{3}$ Institut de Recherche Expérimentale et Clinique (IREC), Département d'obstétrique, Saint-Luc University Hospital, Université catholique de Louvain (UCLouvain), Brussels, Belgium.

Received: 2 April 2019 Accepted: 29 July 2019

\section{Published online: 15 August 2019}

\section{References}

1. Kinney MV, Kerber KJ, Black RE, Cohen B, Nkrumah F, Coovadia H, et al. Sub -Saharan Africa's mothers, newborns, and children: where and why do they die? PLoS Med. 2010;7(6):e1000294 https://www.ncbi.nlm.nih.gov/pmc/ articles/PMC2888581/. Accessed 20 Mar 2019.

2. Firoz T, Sanghvi H, Merialdi M, von Dadelszen P. Pre-eclampsia in low and middle income countries. Best Pract Res Clin Obstet Gynaecol. 2011;25(4): $537-48$

3. Goldenberg RL, Jones B, Griffin JB, Rouse DJ, Kamath-Rayne BD, Trivedi N, et al. Reducing maternal mortality from preeclampsia and eclampsia in lowresource countries--what should work? Acta Obstet Gynecol Scand. 2015; 94(2):148-55. https://obgyn.onlinelibrary.wiley.com/doi/full/10.1111/ aogs.12533. Accessed 20 Mar 2019.

4. Goldenberg RL, McClure EM, Macguire ER, Kamath BD, Jobe AH. Lessons for low-income regions following the reduction in hypertension-related maternal mortality in high-income countries. Int J Gynaecol Obstet Off Organ Int Fed Gynaecol Obstet. 2011;113(2):91-5.

5. Moodley J. Maternal deaths due to hypertensive disorders in pregnancy. Best Pract Res Clin Obstet Gynaecol. 2008;22(3):559-67.
6. Rolnik DL, Wright D, Poon LC, O'Gorman N, Syngelaki A, de Paco Matallana $C_{1}$ et al. Aspirin versus placebo in pregnancies at high risk for preterm preeclampsia. N Engl J Med. 2017;377(7):613-22 https://www.nejm.org/doi/ full/10.1056/NEJMoa1704559. Accessed 20 Mar 2019.

7. Greene MF, Solomon CG. Aspirin to prevent preeclampsia. N Engl J Med. 2017;377(7):690-1 https://www.nejm.org/doi/full/10.1056/NEJMe1708920. Accessed 20 Mar 2019

8. Moore GS, Allshouse AA, Post AL, Galan HL, Heyborne KD. Early initiation of low-dose aspirin for reduction in preeclampsia risk in high-risk women: a secondary analysis of the MFMU high-risk aspirin study. J Perinatol. 2015; 35(5):328-31 https:/www.ncbi.nlm.nih.gov/pmc/articles/PMC4838902/. Accessed 20 Mar 2019.

9. Rolnik DL, O'Gorman N, Roberge S, Bujold E, Hyett J, Uzan S, et al. Early screening and prevention of preterm pre-eclampsia with aspirin: time for clinical implementation. Ultrasound Obstet Gynecol. 2017;50(5):551-6 https://obgyn.onlinelibrary.wiley.com/doi/full/10.1002/uog.18899. Accessed 20 Mar 2019.

10. Okusanya BO, Oladapo OT, Long Q, Lumbiganon P, Carroli G, Qureshi Z, et al. Clinical pharmacokinetic properties of magnesium sulphate in women with pre-eclampsia and eclampsia. BJOG Int J Obstet Gynaecol. 2016;123(3):356-66.

11. Khooshideh M, Ghaffarpour M, Bitarafan S. The comparison of anti-seizure and tocolytic effects of phenytoin and magnesium sulphate in the treatment of eclampsia and preeclampsia: a randomised clinical trial. Iran J Neurol. 2017;16(3):125-9.

12. Mone F, Mulcahy C, McParland P, McAuliffe FM. Should we recommend universal aspirin for all pregnant women? Am J Obstet Gynecol. 2017;216(2): 141.e1-141141.e5.

13. National Institute for. Health and clinical excellence: guidance. Hypertension in pregnancy: the Management of Hypertensive Disorders during Pregnancy. London, UK: RCOG Press; 2010.

14. Milne F, Redman C, Walker J, Baker P, Bradley J, Cooper C, et al. The pre -eclampsia community guideline (PRECOG): how to screen for and detect onset of pre-eclampsia in the community. BMJ. 2005;330(7491):576-80 http:// www.ncbi.nlm.nih.gov/pmc/articles/PMC554032/. Assessed 20 Mar 2019.

15. World Health Organization. WHO recommendations on antenatal Care for a Positive Pregnancy Experience. Geneva: World Health Organization; 2016.

16. Magee LA, Pels A, Helewa M, Rey E, von Dadelszen P. Canadian hypertensive disorders of pregnancy working group. Diagnosis, evaluation, and management of the hypertensive disorders of pregnancy: executive summary. J Obstet Gynaecol Can JOGC. 2014;36(5):416-41. https://www. jogc.com/article/S1701-2163(15)30588-0/fulltext. Accessed 20 Mar 2019.

17. Brown MA, Magee LA, Kenny LC, Karumanchi SA, McCarthy FP, Saito S, et al. The hypertensive disorders of pregnancy: ISSHP classification, diagnosis \& management recommendations for international practice. Pregnancy Hypertens. 2018;13:291-310. https://www.ahajournals.org/doi/full/10.1161/ HYPERTENSIONAHA.117.10803. Accessed 20 Mar 2019.

18. American College of Obstetricians and Gynecologists, Task Force on Hypertension in Pregnancy. Hypertension in pregnancy. Report of the American College of Obstetricians and Gynecologists' task force on hypertension in pregnancy. Obstet Gynecol. 2013;122(5):1122-31.

19. Kyei NNA, Chansa C, Gabrysch S. Quality of antenatal care in Zambia: a national assessment. BMC Pregnancy Childbirth. 2012;12:151 https://www. ncbi.nlm.nih.gov/pmc/articles/PMC3536568/. Accessed 20 Mar 2019.

20. Benova L, Tunçalp Ö, Moran AC, Campbell OMR. Not just a number: examining coverage and content of antenatal care in low-income and middle-income countries. BMJ Glob Health. 2018;3(2):e000779 https://www. ncbi.nIm.nih.gov/pmc/articles/PMC5898334/. Accessed 20 Mar 2019.

21. Betrán AP, Bergel E, Griffin S, Melo A, Nguyen MH, Carbonell A, et al. Provision of medical supply kits to improve quality of antenatal care in Mozambique: a stepped-wedge cluster randomised trial. Lancet Glob Health. 2018;6(1):e57-65 https://www.ncbi.nlm.nih.gov/pmc/articles/PMC5 732314/. Accessed 20 Mar 2019.

22. Kanyangarara M, Munos MK, Walker N. Quality of antenatal care service provision in health facilities across sub-Saharan Africa: evidence from nationally representative health facility assessments. J Glob Health. 2017;7(2):021101 https:/www.ncbinlm.nih.gov/pmc/articles/PMC5680531/. Accessed 20 Mar 2019.

23. Marchant T, Tilley-Gyado RD, Tessema T, Singh K, Gautham M, Umar N, et al. Adding content to contacts: measurement of high quality contacts for maternal and newborn health in Ethiopia, north East Nigeria, and Uttar Pradesh. India PloS One. 2015;10(5):e0126840 https://www.ncbi.nlm.nih.gov/ pmc/articles/PMC4441429/. Accessed 20 Mar 2019. 
24. Ejigu T, Woldie M, Kifle Y. Quality of antenatal care services at public health facilities of Bahir-Dar special zone, Northwest Ethiopia. BMC Health Serv Res. 2013;13:443 https://www.ncbi.n/m.nih.gov/pmc/articles/PMC4231347/. Accessed 20 Mar 2019.

25. Rawlins B, Plotkin M, Rakotovao JP, Getachew A, Vaz M, Ricca J, et al. Screening and management of pre-eclampsia and eclampsia in antenatal and labor and delivery services: findings from cross-sectional observation studies in six sub-Saharan African countries. BMC Pregnancy Childbirth. 2018;18(1):346 https://www.ncbi.nlm.nih.gov/pmc/articles/PMC6108136/. Accessed 20 Mar 2019

26. Ministère du Plan et Suivi de la Mise en œuvre de la Révolution de la Modernité (MPSMRM), Ministère de la Santé Publique, ICF International. Enquête Démographique et de Santé en République Démocratique du Congo 2013-2014. Rockville, Maryland. USA : MPSMRM, MSP et ICF International, 2014. https://dhsprogram.com/pubs/pdf/FR300/FR300.pdf. Accessed 20 Mar 2019.

27. World Health Organization, UNICEF, United Nations, Department of Economic and Social Affairs, Population Division, World Bank. Trends in maternal mortality: 1990 to 2015: estimates by WHO, UNICEF. UNFPA: World Bank Group and the United Nations Population Division. Geneva. Geneva. p. 2015.

28. République Démocratique du Congo. Ministère de la Santé. Système National d'Information Sanitaire. Kinshasa, 2017.

29. République Démocratique du Congo. Ministère de la Santé. Bulletin №1 de la surveillance des décès maternels et riposte (SDMR). Kinshasa; 2018. https://drc.unfpa.org/sites/default/files/pub-pdf/BULLETIN\%20SEMESTRIEL\%2 0N\%201\%20SDMR-RDCONGO.pdf. Accessed 20 Mar 2019.

30. United Nations General Assembly. Transforming our world: the 2030 agenda for sustainable development. New York; 2015

31. République Démocratique du Congo. Ministère de la Santé. Recueil des normes de la zone de santé. Kinshasa, 2006. https://www.who.int/hac/ techguidance/training/analysing_health_systems/5_normes_de_la_zone _de_sante_06.pdf. Accessed 20 Mar 2019.

32. Kleinbaum DG, Kupper LL, Nizam A, Muller KE. Applied regression analysis and other multivariable methods. 4th edition. Australia; Belmont, CA: Duxbury Press; 2007.

33. Saad-Haddad G, DeJong J, Terreri N, Restrepo-Méndez MC, Perin J, Vaz L, et al. Patterns and determinants of antenatal care utilization: analysis of national survey data in seven countdown countries. J Glob Health. 2016; 6(1):010404. https://www.ncbi.n/m.nih.gov/pmc/articles/PMC4871063/. Accessed 20 Mar 2019.

34. Joshi C, Torvaldsen S, Hodgson R, Hayen A. Factors associated with the use and quality of antenatal care in Nepal: a population-based study using the demographic and health survey data. BMC Pregnancy Childbirth. 2014;14:94 https://www.ncbi.nlm.nih.gov/pmc/articles/PMC3943993/. Accessed 20 Mar 2019.

35. Ansari N, Manalai P, Maruf F, Currie S, Stekelenburg J, van Roosmalen J, et al. Quality of care in early detection and management of pre-eclampsia/ eclampsia in health facilities in Afghanistan. BMC Pregnancy Childbirth. 2019;19(1):36 https://www.ncbi.n/m.nih.gov/pmc/articles/PMC6339332/. Accessed 20 Mar 2019

36. Nkamba D, Mwenechanya M, Kilonga AM, Cafferata ML, Berrueta AM, Mazzoni A, et al. Barriers and facilitators to the implementation of antenatal syphilis screening and treatment for the prevention of congenital syphilis in the Democratic Republic of Congo and Zambia: results of qualitative formative research. BMC Health Serv Res. 2017;17: 556 https://www.ncbi.nlm.nih.gov/pmc/articles/PMC5556622/. Accessed 20 Mar 2019

37. Warren C, Hossain S, Rahat AN, Sultana K, Kirk K, Dempsey A. Landscape report on pre-eclampsia and eclampsia in Bangladesh. Washington, DC: Population Council; 2015. http://www.endingeclampsia.org/wp-content/ uploads/2017/04/FINAL-LandcapeAnalysis-Bangladesh-USAID-GA31 -EndingEclampsia-Mar2016.pdf. Assessed 20 Mar 2019.

38. Warren C, Salisu Ishaku, Ayodeji B. O, Adoyi G, Karen R. K, Amy Dempsey. Landscaping analysis for pre-eclampsia and eclampsia in Nigeria. Population Council, Abuja: Federal Capital Territory, 2015. http://www.endingeclampsia. org/wp-content/uploads/2017/04/EndingEclampsia-LandscapeReportNigeria.pdf. Assessed 20 Mar 2019.

39. République Démocratique du Congo, Ministère de la Santé Publique. Normes et directives des interventions intégrées de santé de la mère, du nouveau-né et de l'enfant en République Démocratique du Congo. Volume 1 soins : obstétricaux essentiels. Kinshasa; 2012. http://www.mediacongo. net/docs/jobaof/2014/oms_20141202_SMNE.pdf.
40. Ecole de Santé Publique de l'Université de Kinshasa, République Démocratique du Congo et ICF. Evaluation des Prestations des Services de soins de Santé (EPSS RDC) 2017-2018. Kinshasa, RDC et Rockville, Maryland, USA : ESPK et ICF. ; 2019. https://dhsprogram.com/pubs/pdf/SR258/SR258.pdf. Assessed 20 Mar 2019.

41. Salam RA, Das JK, Ali A, Bhaumik S, Lassi ZS. Diagnosis and management of preeclampsia in community settings in low and middle-income countries. J Fam Med Prim Care. 2015;4(4):501-6 http://www.ncbi.nlm.nih.gov/pmc/ articles/PMC4776599/. Accessed 20 Mar 2019.

42. Mpunga D, Lumbayi JP, Dikamba N, Mwembo A, Ali Mapatano M, Wembodinga G. Availability and Quality of Family Planning Services in the Democratic Republic of the Congo: High Potential for Improvement. Glob Health Sci Pract. 2017;5(2):274-85 https://www.ncbi.n/m.nih.gov/pmc/ articles/PMC5487089/. Assessed 20 Mar 2019.

43. Nsibu CN, Manianga C, Kapanga S, Mona E, Pululu P, Aloni MN. Determinants of antenatal care attendance among pregnant women living in endemic malaria settings: experience from the Democratic Republic of Congo. Obstet Gynecol Int 2016 :5423413. https://www.ncbi.nlm.nih.gov/ pmc/articles/PMC5040812/. Assessed 20 Mar 2019.

44. Tandu-Umba B, Mbangama MA, Kamongola KMB, Kamgang Tchawou AG, Kivuidi MP, Kasonga Munene S, et al. Pre-pregnancy high-risk factors at first antenatal visit: how predictive are these of pregnancy outcomes? Int J Women's Health. 2014;6:1011-8 https://www.ncbi.nlm.nih.gov/pmc/articles/ PMC4266255/. Accessed 20 Mar 2019.

45. Althabe F, Chomba E, Tshefu AK, Banda E, Belizán M, Bergel E, et al. A multifaceted intervention to improve syphilis screening and treatment in pregnant women in Kinshasa, Democratic Republic of the Congo and in Lusaka, Zambia: a cluster randomised controlled trial. Lancet Glob Health 2019 ; e1-9 https://www.thelancet.com/journals/langlo/article/PIIS2214-1 09X(19)30075-0/fulltext. Accessed 28 Mar 2019.

\section{Publisher's Note}

Springer Nature remains neutral with regard to jurisdictional claims in published maps and institutional affiliations.
Ready to submit your research? Choose BMC and benefit from:

- fast, convenient online submission

- thorough peer review by experienced researchers in your field

- rapid publication on acceptance

- support for research data, including large and complex data types

- gold Open Access which fosters wider collaboration and increased citations

- maximum visibility for your research: over $100 \mathrm{M}$ website views per year

At BMC, research is always in progress.

Learn more biomedcentral.com/submissions 